\title{
Guideline of Guidelines: follow-up after nephrectomy for renal cell carcinoma
}

Timothy J Williamson ${ }^{1}$, John R Pearson ${ }^{1}$, Joseph Ischia $^{1}$, Damien M Bolton ${ }^{1}$, Nathan Lawrentschuk ${ }^{1,2,3}$

1. University of Melbourne, Department of Surgery, Austin Hospital, Melbourne, Victoria, Australia

2. Peter MacCallum Cancer Centre, Division of Cancer Surgery, Melbourne, Australia

3. Olivia Newton-John Cancer Research Institute, Austin Hospital, Melbourne, Victoria, Australia

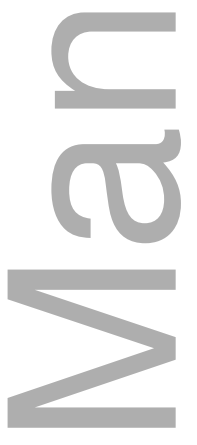

Correspondence:

Nathan Lawrentschuk

lawrentschuk@gmail.com

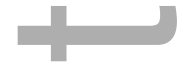

Key words: Kidney Neoplasms, Nephrectomy, Guideline, Recurrence, Outcomes

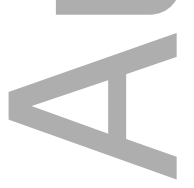

This is the author manuscript accepted for publication and has undergone full peer review but has not been through the copyediting, typesetting, pagination and proofreading process, which may lead to differences between this version and the Version of Record. Please cite this article as doi: 10.1111/bju.13384

This article is protected by copyright. All rights reserved 
Received Date : 14-Jul-2015

Revised Date : 20-Oct-2015

Accepted Date : 23-Nov-2015

Article type : Review

\begin{abstract}
AIM; To review and compare the international guidelines and surveillance protocols for postnephrectomy renal cell carcinoma (RCC) METHOD; PubMed database searches were conducted according to the PRISMA statement in order to identify current international surveillance guidelines and surveillance protocols for surgically treated and clinically localized RCC. RESULTS; 17 articles were reviewed with 3 urological endorsed guidelines, 3 oncological and 11 proposed strategies. Guidelines and strategies varied significantly in relation to follow-up, specifically the frequency and timing of radiological imaging. CONCLUSION; Although there is currently no consensus within the literature regarding surveillance protocols, various guidelines and strategies have been developed using both patient and tumour characteristics. KEY WORDS; Kidney Neoplasms, Nephrectomy, Guideline, Recurrence, Outcomes
\end{abstract}

\title{
Introduction
}

Worldwide the incidence of renal cancer at all stages is increasing and contributes $3 \%$ of all new adult malignancies [1,2]. Curative intention with surgical resection, either nephron sparing or radical, is the mainstay of treatment for clinically localized disease with rates of recurrence reported between 20-30\% [3]. These high rates of recurrence, combined with the necessity of early detection to increase the chance of favorable outcomes, underscore the importance of posttreatment surveillance. The development of follow-up guidelines endorsed by several respected organisations has been achieved through comprehensive reviews of the literature.

\section{Rationale}

As with most malignancies, surveillance protocols after surgical resection of the primary tumour focuses on the identification of three key outcomes; oncological control, functional preservation and survivorship. Understanding the natural history of kidney neoplasms as well as the chronology, sites and prognostic indicators of tumour recurrence help predict the likelihood and timing of disease relapse. 
Functional outcomes after nephrectomy are measured largely by the preservation of renal function as well as the development of post-operative sequelae. Survivorship encompasses both the physical wellbeing of the patient as well as the psychosocial impact of treatment and follow-up. Finally, understanding the different modalities for detecting disease recurrence, and their risks and benefits, is important when planning follow-up with significant resource implications for the healthcare system.

Currently there are no agreed upon follow-up guidelines in many jurisdictions and it is the aim of this article to compare current international guidelines available in the literature. The American Urological Association (AUA) released a comprehensive set of guidelines in 2013 [4]. The European Association of Urology (EAU) released a full text update of their Renal Cell Carcinoma guidelines in 2013 with a partial update in 2014 [5]. The Canadian Urological Association (CUA) released guidelines in 2008 with the most recent consensus update in 2011 [6]. The National Comprehensive Cancer Network (NCCN) released guidelines in 2014 with an update in early 2015 [7]. In presenting this review, we hope to distil the information and bring consensus to follow-up of patients undergoing nephrectomy.

\section{Methods}

A systematic review was conducted in March 2015, with an update in October 2015, based on the guidelines outlined by the PRISMA statement for reporting systematic reviews [8]. Utilizing the PubMed database and synonyms for the search terms "renal cell carcinoma", "follow-up" and "guidelines", articles were identified pertaining to post-nephrectomy surveillance for localised disease. Articles regarding advanced or metastatic disease were excluded. In cases where multiple guidelines were identified from a common publisher the most recently updated version was included. 'Cascading' was used to identify relevant and significant publications from references cited in these articles that were not previously included in the search.

\section{Results}


Results are summarized in Appendix 1. Of the 336 articles retrieved from the search, 75 pertained to non-metastatic RCC treated with nephrectomy. 17 of these articles contained follow-up protocols with three (3) endorsed by urological associations, four (4) by oncological associations and 11 by single institutions. Non-English articles (9) and articles superseded by updated versions (7) were excluded. There were a number of articles concerning prognostic indicators for recurrent disease, however, these did not outline recommendations for follow-up and were not included in the review. Among the recommendations, nine (9) protocols were based on tumour stage (including the AUA, CUA and NCCN), five (5) on integrated prognostic algorithms (including the EAU) and three (3) were generalized recommendations.

\section{Components of follow-up}

Prognostic factors for recurrent disease

A number of tumour characteristics have been well studied and shown to be important predictive factors for RCC recurrence. These include tumor stage, nuclear grade, overall performance status and molecular markers[9]. The tumour, nodes, metastases (TNM) system is historically the best tool for prognosis and therefore the most extensively used when researching and developing surveillance protocols. Using this system, for stages I to IV, the 5-year cancer survival rates have been reported to be $91 \%, 74 \%, 67 \%$, and $32 \%$ respectively [9]. Other studies report similar findings with pathological tumour stage highly related to cancer specific survival [10-14]. Tumour grade has also been shown to be an independent predictor of recurrence with 5 year survival rates of $89 \%, 65 \%$, and $46 \%$ for Fuhrman nuclear grades of 1,2 , and 3 to 4 , respectively [9]. Other prognostic factors that have been researched and included into various recurrence protocols include patient symptoms, tumour size, tumour necrosis and microvascular invasion [10].

\section{Chronology and site of relapse}

The timing and sites of tumour recurrence are important factors for directing clinically beneficial surveillance strategies. In general RCC behaves similarly to most malignancies with the greatest risk of recurrence occurring early. The median time to relapse was shown to be within 1 to 2 years with most recurrences 
occurring within 3 years following surgery [14-16]. Several case reports exist in the literature of recurrences occurring 10 years or more after initial nephrectomy [1720], however, recurrences occurring after a longer time interval generally appeared to be associated with a better prognosis [13]. Furthermore, the timing of disease recurrence has an inverse relationship with tumour stage, with Levy et al [11] reporting median times to recur of 38, 32 and 17 months for T1, T2 and T3 tumours respectively. Similar findings were found in several other reports $[9,13$, $14,21]$.

Tumour recurrence develops through haematogenous spread and although RCC can metastasize to virtually anywhere within the body, lung metastases have been identified as the most common with site-specific incidence rates of 3-16\% being reported in the literature $[11,12,14,21]$. The disparity in reported recurrence rates was thought to be due to variations in patient selection. Other common sites for disease progression are bone, liver, brain and local recurrence in the renal fossa / renal remnant as well as a $2-4 \%$ risk of metachronous disease in the contralateral kidney [9]. With the exception of bone and brain metastases, the majority of disease recurrences were identified in asymptomatic patients.

\section{Modalities for detecting disease recurrence}

Radiological imaging is generally the most useful component of a follow-up regimen for detecting disease recurrence. Most relapses are found when the patient is asymptomatic due to the nature of the disease and the widespread use of imaging modalities. Follow-up regimens consisting of history and physical examination, laboratory tests and radiological imaging are suggested at each visit in virtually all guidelines, however, with variations in both type and frequency of imaging throughout. Given the likely sites of recurrence, chest and abdominal imaging is most frequently performed on a routine basis whilst computed tomography (CT) head or bone scan is not routinely recommended unless clinically indicated [22]. CT has both advantages and disadvantages concerning sensitivity, radiation exposure and cost of procedure. CT is more likely to identify early recurrences more amenable to surgical resection compared to CXR, although it is also more likely to identify incidental non-metastatic findings [23]. Furthermore, radiation exposure is greatest with CT, more so with abdominal 
imaging compared to pulmonary, and alternatives should be considered in younger patients likely to require multiple scans. Ultrasound scanning (US) has been recommended in some guidelines for the detection of intra-abdominal recurrences but hasn't been proven to be as sensitive as CT [23]. Magnetic resonance imaging (MRI) is often seen as being acceptable with regards to sensitivity (MRI 71.9\% versus CT $88.5 \%, P<.001$ ) [24] and beneficial in terms of radiation exposure, but has more resource limitations than conventional imaging modalities.

\section{Evaluation of ongoing or potential post-operative complications}

The monitoring of post-operative sequelae in patients with renal neoplasms is an important component of a follow-up visit. Amongst these, the assessment of renal function is often a primary concern. Although the contribution of iatrogenic renal dysfunction related to surgery is not entirely clear, the identification of patients at risk of chronic kidney disease (CKD) is an important clinical consideration and requires appropriate assessment [25]. The majority of guidelines recommend regular serum creatinine measurement and calculation of individual estimated glomerular filtration rate (eGFR) to assess renal function. The early identification and medical management of patients at risk of CKD should be a priority to prevent or delay the progression of this disease.

\section{Surveillance guidelines}

There is currently insufficient evidence to suggest that follow-up protocols will lead to earlier treatment and better outcomes in early RCC. This is primarily due to a lack of randomized prospective studies in the field. The European Society for Medical Oncology (ESMO) therefore states no standard recommendation can be given and follow-up should be based on patient risk factors and possible treatment options upon recurrence [26]. Despite this, several institutions have developed risk stratified protocols based on large nonrandomized cohorts studies of the TNM staging system and integrated prognostic algorithms. For the recommendations discussed below the AUA, CUA and NCCN stratify patients into groups based on TNM staging system alone. The EAU however suggests separating patients into low, intermediate and high risk groups based on one of the available risk stratification models but does not give preference to a single model. Where available, the level of evidence (LE), grade of recommendation (Grade) or 
Categories of Evidence (Category) is given in the following review of existing guidelines.

Review of nationally endorsed protocols: The AUA, EAU, CUA and NCCN. Low risk disease

For clinically localised T1 stage disease many guidelines suggest less frequent follow-up due to the low risk of recurrence (figure 1). The AUA recommends yearly CXR for 3 years (Grade C, AUA) [4] then clinically indicated beyond that whilst the CUA guideline extends yearly CXR to 6 years [6]. The rationale being that the most common site for metastases are pulmonary and early identification leads to a more favorable outcome when they are found to be the sole site of recurrence [4]. These groups recommended CXR compared to CT due to the lower rate of false positive and benign findings requiring invasive work-ups seen with plain radiography (Grade C, AUA, CUA). In contrast, the EAU comments on the poor sensitivity of CXR for small pulmonary metastases (LE: 4, EAU) and recommends $C T$ of the chest at 1, 3 and 5 years as an alternative for low risk disease [5]. The NCCN recommends annual chest imaging for 3 years and then clinically indicated but doesn't preference one imaging modality over another (Category 2B, NCCN) [7].

For abdominal surveillance in low risk patients the AUA recommends imaging at yearly intervals for 3 years with US, CT or MRI. However, due to the less than $5 \%$ risk of local (renal remnant or renal fossa) or regional recurrence in this group these guidelines are stated as optional (Grade C, AUA) [9]. The CUA extends the time between abdominal CT scanning to 2 and 6 years (Grade C, CUA) whilst the EAU suggests alternating abdominal CT scanning with ultrasound of the abdomen, kidney and renal bed at 6 months then yearly until 5 years. After this point the EUA states patients with low risk disease can be discharged. For radically treated patients the NCCN allows abdominal imaging to be performed at the physicians discretion (Category 2B, NCCN) following a negative postoperative scan. Before the 2014 update the NCCN gave no recommendations beyond a 6 monthly abdominal and chest baseline for radiological imaging [27]. 
Regarding non-imaging surveillance, the AUA advocates for regular history $(\mathrm{Hx})$, physical examination (PE) and laboratory investigations including blood urea nitrogen creatinine ratio (BUN/creatinine), urine analysis (UA) and estimated glomerular filtration rate (eGFR). The NCCN recommends $\mathrm{Hx}$ and PE as well as a comprehensive metabolic panel 6 monthly for 2 years then yearly until 5 years (Category 2B, NCCN). The CUA recommends yearly $\mathrm{Hx}, \mathrm{PE}$ and blood tests consisting of a complete blood count, serum chemistries and liver function tests for 6 years. The latest update from the EAU doesn't comment on the frequency for non-imaging surveillance.

\section{Partial Nephrectomy}

For patients who have undergone a partial nephrectomy (PN), the AUA recommends an abdominal CT or MRI as a baseline within 3 to 12 months following surgery (Expert opinion, AUA) [4]. The rationale for baseline imaging is that it provides a reference for comparison with future scans following alteration to the kidney architecture whilst also monitoring for potential post-operative complications. For radically treated patients, the AUA states a baseline scan can also be performed but allows the use of US. The NCCN similarly advocates for baseline imaging within 3-12 months following surgery but includes USS as an option for PN. The CUA states a baseline CT 3 months after surgery is optional as is further yearly abdominal imaging with US (Grade D, CUA) [22]. Comparably the NCCN and AUA both recommend additional imaging at yearly intervals with US, CT or MRI for 3 years following a negative baseline scan. The EAU doesn't make a distinction between radical and partially treated patients, presumably due to the similar recurrence rates reported between the two groups [28]. The 2014 update, however, warns of an increased risk of intra-renal recurrence with larger tumours $(>7 \mathrm{~cm})$ treated with partial nephrectomy (Grade C, EAU) and therefore advises a more intensive follow-up regimen be applied.

\section{Moderate to high risk disease}

For moderate to high risk tumours intensive surveillance regimens are recommended (see figure 2, figure 3). This is due to the increased risk of both local recurrence and metastatic progression in these groups, with reported rates of $30-70 \%$ [4]. After a baseline chest and abdominal CT scan (T2-4 NO or any 
stage $\mathrm{N}+$ ), further imaging to detect pulmonary and abdominal recurrences is recommended by the AUA and NCCN at 6 monthly intervals for the first 3 years and yearly until 5 years (Grade C, AUA. Category 2B, NCCN). Due to the paucity of comparable studies in the field the AUA was not able to make recommendations for follow-up beyond 5 years. Neither the AUA or NCCN gave preference over CXR or CT for the ongoing detection of pulmonary metastases. The NCCN reported category 2B evidence for the use of US for detecting stage T3 abdominal recurrences [7].

Comparably, the CUA guidelines recommend 6 monthly CXR for 6 years but suggest less frequent abdominal imaging for T2 tumours at 1,3 and 5 years (Grade C, CUA). In a 2009 update the CUA included the option of using US in place of CT for low risk (T1-T2) asymptomatic patients [6]. More frequent surveillance for T3 stage disease is recommended with an abdominal CT performed 6 monthly for the first 2 years and yearly thereafter (Grade C, CUA). The CUA guidelines made a similar recommendation to the AUA regarding long term follow-up, with surveillance based on individual patient factors. The EAU recommends $\mathrm{CT}$ of the chest and abdomen twice in the first year and yearly thereafter until 5 years for high risk groups. For patients with intermediate disease USS was recommended as an alternative to CT in the third year to reduce radiation exposure. Beyond 5 years the EAU recommends CT of the chest and abdomen to be performed once every 2 years for both intermediate and high risk groups.

The EAU and AUA both comment on the increased risk of recurrence when there is a positive margin following surgery and recommend patients follow the high risk protocols in these cases (Grade C, EAU, AUA)

\section{Follow-up for small renal masses (SRM) not treated with surgery}

Alternative management strategies for SRMs $(<4 \mathrm{~cm})$ have become more widely adopted and require specialized surveillance considerations. Active surveillance is often considered in elderly and infirm patients where there is an increased risk with surgical intervention or those with reduced life expectancy. Due to the reported slow growth (average $0.13 \mathrm{~cm} / \mathrm{yr}$ ) [29] and rare metastatic progression 
$(<2 \%)[29,30]$ of SRMs, surgical intervention can be delayed in these patients until clinical progression is displayed. Ablative therapies are an option for patients where surgery is undesired or when co-morbidities make surgery unsuitable. Cryotherapy (CA) and radiofrequency ablation (RFA) are the most commonly used techniques. Most guidelines suggest a biopsy be performed before or at the time of treatment. Re-biopsy or surgical intervention should be considered if the lesion fails to regress over time, increases in size or a new nodularity or lesion is identified.

Active surveillance

The AUA recommends a biopsy dependent follow-up protocol for active surveillance [4]. Small neoplasms with biopsy proven renal carcinoma, oncocytoma, oncocytic neoplasms or with indeterminate histology are recommended to be followed with a cross sectional abdominal image (CT or MRI) 6 months after initiation of active surveillance to establish a growth rate [4]. Benign neoplasms on biopsy are followed in the same way as low risk malignant lesions due to the risk of local growth causing compression or invasion of surrounding structures as well as the diagnostic difficulty of differentiating oncocytoma from oncocytic neoplasms (chromophobe subtype). Additional abdominal imaging is recommended at yearly intervals thereafter with $\mathrm{CT}, \mathrm{MRI}$ or US. For biopsy proven renal carcinoma annual CXR is also recommended. The imaging recommendations from the NCCN are similar to that of the AUA, however the NCCN cites a retrospective study stating all imaging modalities accurately predict tumour size, whereas the AUA suggests CT or MRI as being superior to US for SRMs.

The EAU suggests stricter follow-up with CT, MRI or US at 3 and 6 months post initiation of active surveillance and then 6 monthly until 3 years, and annually thereafter [5]. The CUA released a recent review citing a protocol from Rendon et. al. with a greater emphasis on CT imaging to ensure a safe surveillance strategy [30]. They recommended abdominal imaging every 3 months for the first year, every 6 months for the second and third years, and yearly thereafter [30]. Both the EAU and CUA recommended annual CXR for pulmonary surveillance. 
Ablative therapies

Due to a reported $2-10 \%$ failure rate of ablative therapies, early detection of treatment failure is important to maximize re-treatment potential $[4,30]$. For this reason the AUA recommends cross sectional scanning (CT or MRI) with and without contrast at 3 and 6 months following therapy. After radiographic conformation of treatment success abdominal and chest surveillance (CXR) is recommended annually for 5 years with optional further imaging. The NCCN recommendations are similar to that of the AUA whilst the EAU guidelines for CA/RFA follow the post-surgical guidelines for intermediate or high risk nephrectomy groups as illustrated above (figure 2, figure 3). The CUA guidelines suggest abdominal imaging (CT, MRI or US) at 3 to 6 months following treatment and then at 6 to 12 monthly intervals thereafter with annual CXR.

\section{Conclusion}

A number of respected organizations have developed surveillance guidelines for clinically localised RCC. However, due to the paucity of compatible studies in the literature these recommendations generally lack strong levels of evidence for whether the benefits of different surveillance schedules outweigh the potential risks/burdens involved. Instead the majority of recommendations endorsed by national institutions are developed through panel discussion taking into account the current literature as well as the clinical training, experience, knowledge and judgement of its panel members. Understandably this has resulted in considerable differences between published guidelines.

Of note, the mode, frequency and timing of radiological imaging is significantly varied between recommendations. The 2013 guidelines endorsed by the AUA advocates for the use of CXR to monitor pulmonary recurrences whereas the 2014 update by the EAU maintains CT to be more reliable. AUA and NCCN guidelines for low risk disease stop at 3 years of surveillance whereas the EAU continues to 5 years and the CUA to 6 years. The use of abdominal US to detect disease relapse appears in many guidelines but the NCCN states there is a low level of evidence to support its use in higher risk disease (Category 2B for T3) [7]. Although there exists variation amongst guidelines and ultimately the intensity of follow-up will be at the discretion of the clinician following the risk stratification of 
individual patients, it seems pertinent to have clinically justified recommendations that are based on patterns of disease progression and proven to be beneficial in relation to patient outcomes. (governing body)

Finally, whilst the need for further research remains, the authors suggest a unifying recommendation based on the current guidelines and taking into account the supporting levels of evidence (figure 4). These guidelines could be validated using local data for future use. For low risk / T1 disease, a baseline abdominal CT scan at 3 months followed by yearly US or CT until 3 years and a final US or CT at 5 years could be adopted. Chest surveillance could be performed by yearly CXR for 5 years, with chest CT replacing CXR at year 3 and 5 . For intermediate / T2 disease, abdominal surveillance could be performed with baseline CT at 3 months followed by 6 monthly imaging for 3 years then yearly until 5 years, alternating between CT and US. For chest surveillance, 6 monthly imaging could also be performed for 3 years, alternating between CT and CXR, and then yearly until 5 years. For high risk / T3 disease, 6 monthly CT could be performed for abdominal surveillance until 3 years, then yearly until 5 years. Chest surveillance could also be performed at 6 monthly intervals alternating between CT and CXR.

\section{Conflicts of Interest}

None disclosed.

\section{References}

1. Welfare AIoHa. Cancer incidence projections: Australia, 2011 to 2020. Canberra Australian Institute of Health and Welfare 2012.

2. Siegel RL, Miller KD, Jemal A. Cancer statistics, 2015. CA: a cancer journal for clinicians. 2015;65(1):5-29.

3. Janzen NK, Kim HL, Figlin RA, Belldegrun AS. Surveillance after radical or partial nephrectomy for localized renal cell carcinoma and management of recurrent disease. The Urologic clinics of North America. 2003;30(4):843-52.

4. Donat SM, Diaz M, Bishoff JT, et al. Follow-up for Clinically Localized Renal Neoplasms: AUA Guideline. The Journal of urology. 2013;190(2):407-16. 
5. Ljungberg B, Bensalah K, Canfield S, et al. EAU Guidelines on Renal Cell Carcinoma: 2014 Update. European urology. 2015.

6. Jewett M, Finelli A, Kollmannsberger C, et al. Management of kidney cancer: canadian kidney cancer forum consensus update 2011. Can Urol Assoc J. 2012;6(1):16-22.

7. Motzer RJ, Jonasch E, Agarwal N, et al. Kidney cancer, version 2.2014. Journal of the National Comprehensive Cancer Network : JNCCN. 2014;12(2):175-82.

8. Liberati A, Altman DG, Tetzlaff J, et al. The PRISMA statement for reporting systematic reviews and meta-analyses of studies that evaluate health care interventions: explanation and elaboration. Journal of clinical epidemiology. 2009;62(10):e1-34.

9. Lam JS, Shvarts O, Leppert JT, Figlin RA, Belldegrun AS. Renal cell carcinoma 2005: new frontiers in staging, prognostication and targeted molecular therapy. The Journal of urology. 2005;173(6):1853-62.

10. Skolarikos A, Alivizatos G, Laguna P, de la Rosette J. A review on follow-up strategies for renal cell carcinoma after nephrectomy. European urology. 2007;51(6):1490-500; discussion 501.

11. Levy DA, Slaton JW, Swanson DA, Dinney CP. Stage specific guidelines for surveillance after radical nephrectomy for local renal cell carcinoma. The Journal of urology. 1998;159(4):1163-7.

12. Ljungberg B, Alamdari FI, Rasmuson T, Roos G. Follow-up guidelines for nonmetastatic renal cell carcinoma based on the occurrence of metastases after radical nephrectomy. BJU international. 1999;84(4):405-11.

13. Hafez KS, Novick AC, Campbell SC. Patterns of tumor recurrence and guidelines for followup after nephron sparing surgery for sporadic renal cell carcinoma. The Journal of urology. 1997;157(6):2067-70.

14. Stephenson AJ, Chetner MP, Rourke K, et al. Guidelines for the surveillance of localized renal cell carcinoma based on the patterns of relapse after nephrectomy. The Journal of urology. 2004;172(1):58-62.

15. Eggener SE, Yossepowitch O, Pettus JA, Snyder ME, Motzer RJ, Russo P. Renal cell carcinoma recurrence after nephrectomy for localized disease: 
predicting survival from time of recurrence. Journal of clinical oncology : official journal of the American Society of Clinical Oncology. 2006;24(19):3101-6.

16. Klatte T, Lam JS, Shuch B, Belldegrun AS, Pantuck AJ. Surveillance for renal cell carcinoma: why and how? When and how often? Urologic oncology. 2008;26(5):550-4.

17. Abara E, Chivulescu I, Clerk N, Cano P, Goth A. Recurrent renal cell cancer: 10 years or more after nephrectomy. Can Urol Assoc J. 2010;4(2):E45-9.

18. Nagai T, Igase $\mathrm{M}$, Ochi M, et al. [Multiple metastases from renal carcinoma 15 years after nephrectomy]. Nihon Ronen Igakkai zasshi Japanese journal of geriatrics. 2007;44(6):747-51.

19. Riviello C, Tanini I, Cipriani G, et al. Unusual gastric and pancreatic metastatic renal cell carcinoma presentation 10 years after surgery and immunotherapy: A case report and a review of literature. World journal of gastroenterology : WJG. 2006;12(32):5234-6.

20. Lordan JT, Fawcett WJ, Karanjia ND. Solitary liver metastasis of chromophobe renal cell carcinoma 20 years after nephrectomy treated by hepatic resection. Urology. 2008;72(1):230 e5-6.

21. Sandock DS, Seftel AD, Resnick MI. A new protocol for the followup of renal cell carcinoma based on pathological stage. The Journal of urology. 1995;154(1):28-31.

22. Kassouf W, Siemens R, Morash C, et al. Follow-up guidelines after radical or partial nephrectomy for localized and locally advanced renal cell carcinoma. Can Urol Assoc J. 2009;3(1):73-6.

23. Casalino DD, Remer EM, Bishoff JT, et al. ACR appropriateness criteria post-treatment follow-up of renal cell carcinoma. Journal of the American College of Radiology : JACR. 2014;11(5):443-9.

24. Platzek I, Zastrow S, Deppe PE, et al. Whole-body MRI in follow-up of patients with renal cell carcinoma. Acta radiologica. 2010;51(5):581-9.

25. Satasivam P, Reeves F, Rao K, et al. Patients with medical risk factors for chronic kidney disease are at increased risk of renal impairment despite the use of nephron-sparing surgery. BJU international. 2015.

26. Escudier B, Porta C, Schmidinger M, et al. Renal cell carcinoma: ESMO Clinical Practice Guidelines for diagnosis, treatment and follow-up. Annals of 
oncology : official journal of the European Society for Medical Oncology / ESMO. 2014;25 Suppl 3:iii49-56.

27. Motzer RJ, Agarwal N, Beard C, et al. Kidney cancer. Journal of the National Comprehensive Cancer Network : JNCCN. 2011;9(9):960-77.

28. Ljungberg B, Cowan NC, Hanbury DC, et al. EAU guidelines on renal cell carcinoma: the 2010 update. European urology. 2010;58(3):398-406.

29. Jewett M, Rendon R, Dranitsaris G, et al. Does prolonging the time to renal cancer surgery affect long-term cancer control: a systematic review of the literature. The Canadian journal of urology. 2006;13 Suppl 3:54-61.

30. Rendon RA, Kapoor A, Breau R, et al. Surgical management of renal cell carcinoma: Canadian Kidney Cancer Forum Consensus. Can Urol Assoc J. 2014;8(5-6):E398-412.

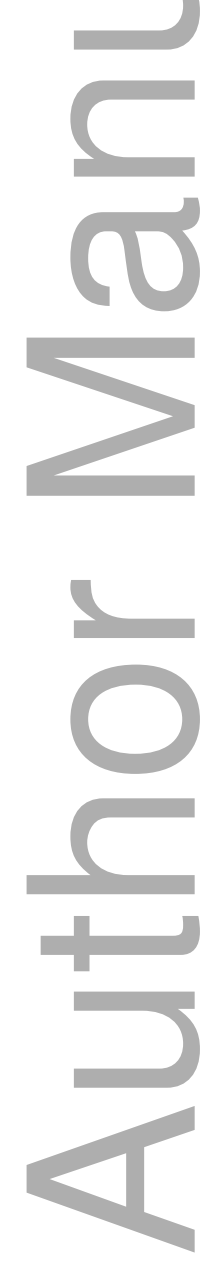

This article is protected by copyright. All rights reserved 


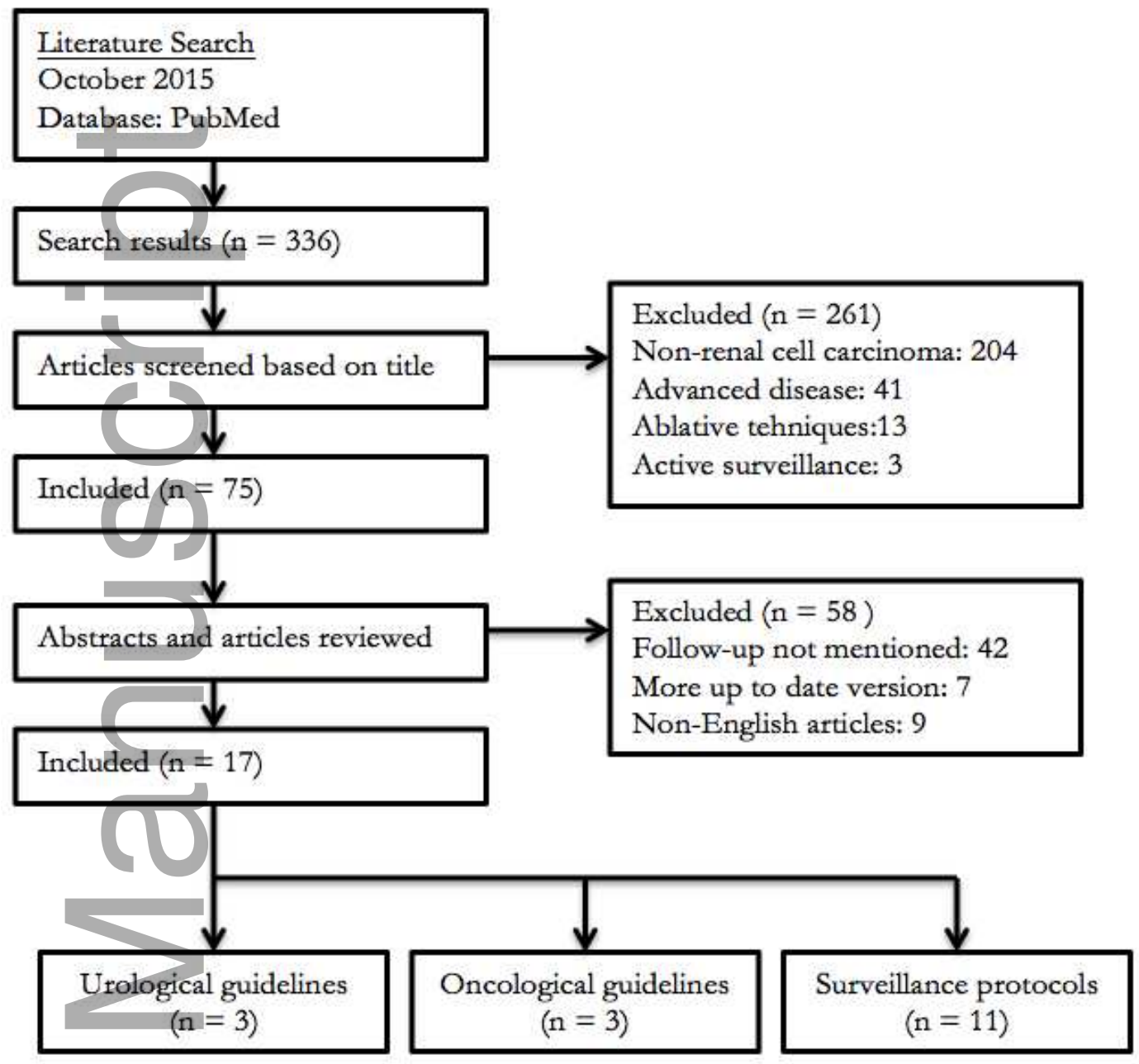

This article is protected by copyright. All rights reserved 


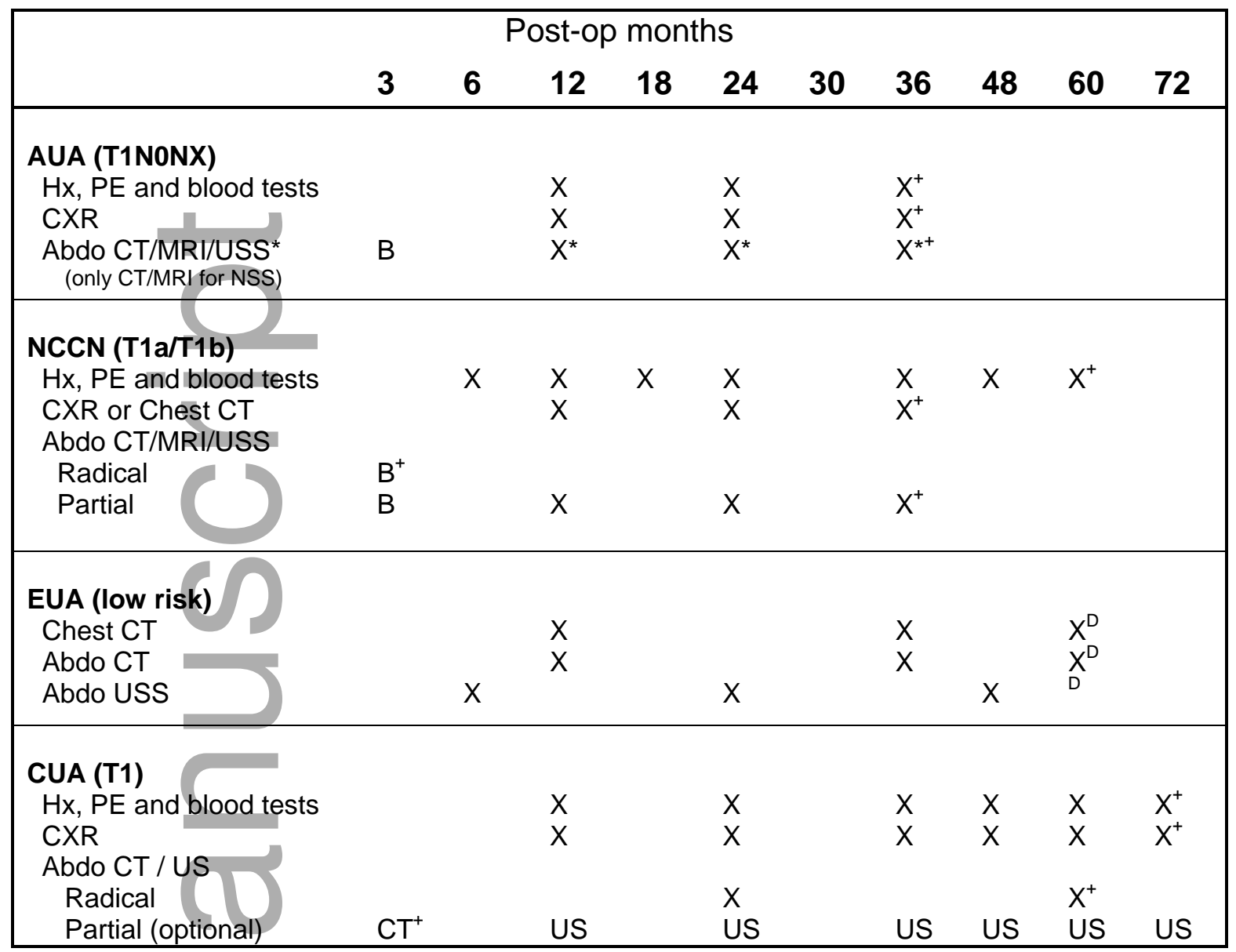

Figure 1: Comparison of International guidelines for low risk/ T1 disease

'B' Baseline. '+' ongoing follow-up under the clinicians discretion, “' optional after baseline, 'D' patients to be discharged

This article is protected by copyright. All rights reserved 


\begin{tabular}{|c|c|c|c|c|c|c|c|c|c|c|}
\hline \multicolumn{11}{|c|}{ Post-op months } \\
\hline & 3 & 6 & 12 & 18 & 24 & 30 & 36 & 48 & 60 & 72 \\
\hline \multicolumn{11}{|l|}{ AUA (T2-4N0, N+) } \\
\hline Hx, PE and blood tests & $\mathrm{X}$ & $\mathrm{x}$ & $\mathrm{X}$ & $\mathrm{X}$ & $\mathrm{X}$ & $\mathrm{X}$ & $\mathrm{X}$ & $\mathrm{X}$ & $\mathrm{X}^{+}$ & \\
\hline CXR or Chest CT & $B^{\wedge}$ & $x$ & $\mathrm{X}$ & $\mathrm{X}$ & $\mathrm{X}$ & $\mathrm{X}$ & $\mathrm{X}$ & $\mathrm{X}$ & $\mathrm{X}^{+}$ & \\
\hline Abdo CT/MRI/US & $\mathrm{B}^{\wedge}$ & $x$ & $\mathrm{x}$ & $\mathrm{x}$ & $X^{*}$ & $\mathrm{x}$ & $\mathrm{x}$ & $x$ & $\mathrm{X}^{+}$ & \\
\hline \multicolumn{11}{|l|}{ NCCN (T2-4N0, N+) } \\
\hline $\mathrm{Hx}, \mathrm{PE}$ and blood tests & $\mathrm{X}$ & $\mathrm{x}$ & $\mathrm{x}$ & $\mathrm{x}$ & $\mathrm{x}$ & $\mathrm{x}$ & $\mathrm{x}$ & $\mathrm{x}$ & $\mathrm{X}^{+}$ & \\
\hline CXR or Chest CT & $B^{\wedge}$ & $\mathrm{x}$ & $\mathrm{X}$ & $\mathrm{X}$ & $\mathrm{X}$ & $\mathrm{X}$ & $\mathrm{X}$ & $\mathrm{x}$ & $\mathrm{X}^{+}$ & \\
\hline Abdo CT/MRI/US & $\mathrm{B}^{\wedge}$ & $x$ & $\mathrm{x}$ & $\mathrm{x}$ & $x$ & $x$ & $x$ & $x$ & $X^{+}$ & \\
\hline \multicolumn{11}{|l|}{ EUA (intermediate risk) } \\
\hline Chest CT & & $\mathrm{x}$ & $\mathrm{X}$ & & $\mathrm{X}$ & & & $\mathrm{X}$ & $x^{2}$ & \\
\hline Abdo CT & & $x$ & $\mathrm{X}$ & & $\mathrm{X}$ & & & $\mathrm{x}$ & $x^{2}$ & \\
\hline Abdo US & & & & & & & $x$ & & & \\
\hline \multicolumn{11}{|l|}{ CUA (T2) } \\
\hline $\mathrm{Hx}, \mathrm{PE}$ and blood tests & & $\mathrm{x}$ & $\mathrm{x}$ & $\mathrm{x}$ & $\mathrm{x}$ & & $x$ & $\mathrm{x}$ & $\mathrm{x}$ & $\mathrm{X}^{+}$ \\
\hline CXR & & $x$ & $x$ & $x$ & $\mathrm{x}$ & & $x$ & $x$ & $X$ & $\mathrm{X}^{+}$ \\
\hline Abdo CT / US & & & $x$ & & & & $\mathrm{X}$ & & $\mathrm{X}^{+}$ & \\
\hline
\end{tabular}

Figure 2: Comparison of International guidelines for intermediate risk/T2 disease.

'B' Baseline. +' ongoing follow-up under the clinicians discretion, ' ${ }^{\wedge}$ ' only CT or MRI for baseline imaging, ' 2 ' indicated every 2 years following 


\begin{tabular}{|c|c|c|c|c|c|c|c|c|c|c|}
\hline \multicolumn{11}{|c|}{ Post-op months } \\
\hline & 3 & 6 & 12 & 18 & 24 & 30 & 36 & 48 & 60 & 72 \\
\hline \multicolumn{11}{|l|}{ AUA (T2-4N0, N+) } \\
\hline Hx, PE and blood tests & $\mathrm{X}$ & $\mathrm{x}$ & $\mathrm{X}$ & $\mathrm{X}$ & $\mathrm{X}$ & $\mathrm{X}$ & $\mathrm{X}$ & $\mathrm{X}$ & $\mathrm{X}^{+}$ & \\
\hline CXR or Chest CT & $\mathrm{B}^{\wedge}$ & $x$ & $\mathrm{X}$ & $\mathrm{X}$ & $\mathrm{X}$ & $\mathrm{X}$ & $\mathrm{X}$ & $\mathrm{X}$ & $\mathrm{X}^{+}$ & \\
\hline Abdo CT/MRI/US & $\mathrm{B}^{\wedge}$ & $x$ & $\mathrm{x}$ & $\mathrm{x}$ & $X^{*}$ & $\mathrm{x}$ & $\mathrm{x}$ & $x$ & $\mathrm{X}^{+}$ & \\
\hline \multicolumn{11}{|l|}{ NCCN (T2-4N0, N+) } \\
\hline $\mathrm{Hx}, \mathrm{PE}$ and blood tests & $\mathrm{X}$ & $\mathrm{x}$ & $\mathrm{x}$ & $\mathrm{x}$ & $\mathrm{x}$ & $\mathrm{x}$ & $\mathrm{x}$ & $\mathrm{x}$ & $\mathrm{X}^{+}$ & \\
\hline CXR or Chest CT & $\mathrm{B}^{\wedge}$ & $\mathrm{x}$ & $\mathrm{X}$ & $\mathrm{X}$ & $\mathrm{X}$ & $\mathrm{X}$ & $\mathrm{X}$ & $\mathrm{x}$ & $\mathrm{X}^{+}$ & \\
\hline Abdo CT/MRI/US & $\mathrm{B}^{\wedge}$ & $x$ & $\mathrm{x}$ & $\mathrm{x}$ & $\mathrm{x}$ & $x$ & $x$ & $x$ & $\mathrm{X}^{+}$ & \\
\hline \multicolumn{11}{|l|}{ EUA (high risk) } \\
\hline Chest CT & & $\mathrm{x}$ & $\mathrm{X}$ & & $\mathrm{X}$ & & $\mathrm{X}$ & $\mathrm{X}$ & $x^{2}$ & \\
\hline Abdo CT & & $x$ & $\mathrm{x}$ & & $\mathrm{x}$ & & $x$ & $x$ & $x^{2}$ & \\
\hline & & & & & & & & & & \\
\hline \multicolumn{11}{|l|}{ CUA (T3) } \\
\hline $\mathrm{Hx}, \mathrm{PE}$ and blood tests & & $\mathrm{x}$ & $\mathrm{X}$ & $\mathrm{X}$ & $\mathrm{X}$ & & $\mathrm{X}$ & $\mathrm{X}$ & $\mathrm{x}$ & $\mathrm{X}^{+}$ \\
\hline CXR & & $x$ & $x$ & $x$ & $x$ & & $x$ & $x$ & $x$ & $X^{+}$ \\
\hline Abdo CT & & $\mathrm{x}$ & $\mathrm{X}$ & $x$ & $\mathrm{X}$ & & & $x$ & $\mathrm{X}^{+}$ & \\
\hline
\end{tabular}

Figure 3: Comparison of International guidelines for high risk/ T3 disease.

'B' Baseline scan. '+' ongoing follow-up under the clinicians discretion. '^' only CT or MRI for baseline imaging, ' 2 ' indicated every 2 years following 


\begin{tabular}{|c|c|c|c|c|c|c|c|c|c|}
\hline \multicolumn{10}{|c|}{ Post-op months } \\
\hline & 3 & 6 & 12 & 18 & 24 & 30 & 36 & 48 & 60 \\
\hline $\begin{array}{l}\text { Low risk / T1 } \\
\text { Hx, PE and blood tests } \\
\text { Chest } \\
\text { Abdomen }\end{array}$ & $\begin{array}{l}X \\
\text { CT }\end{array}$ & & $\begin{array}{l}\mathrm{X} \\
\text { CT } \\
\mathrm{CT} \\
\text { /US }\end{array}$ & & $\begin{array}{l}\text { X } \\
\text { CXR } \\
\text { CT/ } \\
\text { US }\end{array}$ & & $\begin{array}{l}\text { X } \\
\text { CT } \\
\text { CT/ } \\
\text { US }\end{array}$ & $\begin{array}{l}X \\
\text { CXR }\end{array}$ & $\begin{array}{l}\text { X } \\
\text { CT } \\
\text { CT/ } \\
\text { US }\end{array}$ \\
\hline $\begin{array}{l}\text { Intermediate risk / T2 } \\
\text { Hx, PE and blood tests } \\
\text { Chest } \\
\text { Abdomen }\end{array}$ & $\begin{array}{l}X \\
\text { CT }\end{array}$ & $\begin{array}{l}X \\
\text { CXR } \\
\text { US }\end{array}$ & $\begin{array}{l}X \\
\text { CT } \\
\text { CT }\end{array}$ & $\begin{array}{l}X \\
\text { CXR } \\
\text { US }\end{array}$ & $\begin{array}{l}\mathrm{X} \\
\text { CT } \\
\text { CT }\end{array}$ & $\begin{array}{l}X \\
\text { CXR } \\
\text { US }\end{array}$ & $\begin{array}{l}X \\
\text { CT } \\
\text { CT }\end{array}$ & $\begin{array}{l}X \\
\text { CXR } \\
\text { US }\end{array}$ & $\begin{array}{l}\mathrm{X} \\
\mathrm{CT} \\
\mathrm{CT}\end{array}$ \\
\hline $\begin{array}{l}\text { High risk / T3 } \\
\text { Hx, PE and blood tests } \\
\text { Chest } \\
\text { Abdomen }\end{array}$ & $\begin{array}{l}X \\
\text { CT }\end{array}$ & $\begin{array}{l}X \\
\text { CXR } \\
\text { CT }\end{array}$ & $\begin{array}{l}X \\
\text { CT } \\
\text { CT }\end{array}$ & $\begin{array}{l}X \\
\text { CXR } \\
\text { CT }\end{array}$ & $\begin{array}{l}X \\
\text { CT } \\
\text { CT }\end{array}$ & $\begin{array}{l}X \\
\text { CXR } \\
\text { CT }\end{array}$ & $\begin{array}{l}\mathrm{X} \\
\text { CT } \\
\text { CT }\end{array}$ & $\begin{array}{l}X \\
\text { CXR } \\
\text { CT }\end{array}$ & $\begin{array}{l}\mathrm{X} \\
\mathrm{CT} \\
\mathrm{CT}\end{array}$ \\
\hline
\end{tabular}

Figure 4: Unifying recommendations based on current guidelines.

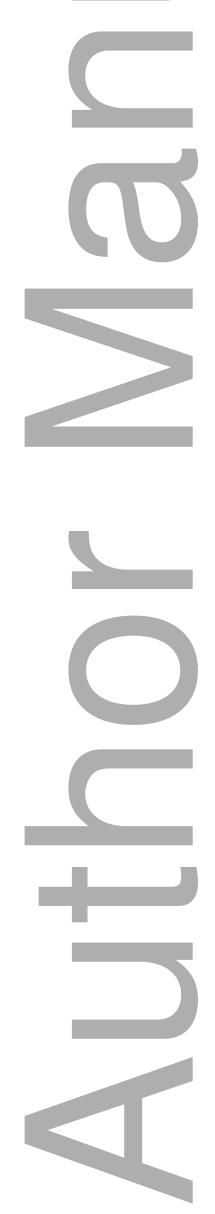

This article is protected by copyright. All rights reserved 


\section{University Library}

\section{- M M N E R VA A gateway to Melbourne's research publications}

Minerva Access is the Institutional Repository of The University of Melbourne

Author/s:

Williamson, TJ;Pearson, JR;Ischia, J;Bolton, DM;Lawrentschuk, N

Title:

Guideline of guidelines: follow-up after nephrectomy for renal cell carcinoma

Date:

2016-04-01

Citation:

Williamson, T. J., Pearson, J. R., Ischia, J., Bolton, D. M. \& Lawrentschuk, N. (2016).

Guideline of guidelines: follow-up after nephrectomy for renal cell carcinoma. BJU

INTERNATIONAL, 117 (4), pp.555-562. https://doi.org/10.1111/bju.13384.

Persistent Link:

http://hdl.handle.net/11343/290805 